\title{
A case of vertical transmission of Chagas disease contracted via blood transfusion in Canada
}

\author{
Margaret A Fearon MD FRCPC ${ }^{1}$, Vito Scalia MSc BSc MLT ${ }^{1}$, Mary Huang RN BScN ${ }^{1}$, Irene Dines MLT ${ }^{1}$, \\ Momar Ndao DVM MSc PhD², Philippe Lagacé-Wiens MD DTMH FRCPC 3
}

\begin{abstract}
MA Fearon, V Scalia, M Huang, I Dines, M Ndao, P LagacéWiens. A case of vertical transmission of Chagas disease contracted via blood transfusion in Canada. Can J Infect Dis Med Microbiol 2013;24(1):32-34.

Chagas disease is caused by the protozoan parasite Trypanosoma cruzi and is endemic in many countries in Latin America, where infected bugs of the Triatominea subfamily carry the parasite in the gut and transmit it to humans through fecal contamination of a bite. However, vertical transmission and transmission through blood transfusion and organ transplantation is well documented. Increasing immigration from endemic countries to North America has prompted blood operators, including Canadian Blood Services and Hema Quebec, to initiate blood donor testing for Chagas antibody. In the present report, an unusual case of vertical transmission from a mother, most likely infected through blood transfusion, and detected as part of a concurrent seroprevalence study in blood donors is described.
\end{abstract}

\section{Un cas de transmission verticale de la maladie de Chagas par transfusion sanguine au Canada}

\begin{abstract}
La maladie de Chagas est causée par le parasite protozoaire Trypanosoma cruzi. Elle est endémique dans de nombreux pays d'Amérique latine, où des insectes infectés de la sous-famille des Triatominea sont porteurs du parasite dans leur intestin et le transmettent aux humains par contamination fécale secondaire à une morsure. Cependant, la transmission verticale, par transfusion sanguine et par transplantation d'organe, est bien étayée. L'immigration croissante de pays endémiques en Amérique du Nord a incité les organismes transfusionnels, y compris la Société canadienne du sang et Héma-Quebec, à amorcer le dépistage de l'anticorps de la maladie de Chagas dans le sang des donneurs. Dans le présent rapport, les chercheurs décrivent un cas inhabituel de transmission verticale par la mère, probablement infectée par une transfusion sanguine, dépistée dans le cadre d'une étude concomitante sur la séroprévalence chez les donneurs de sang.
\end{abstract}

Key Words: Chagas disease; Transfusion transmission; Vertical transmission

$\mathrm{C}$ hagas disease is a zoonotic disease caused by the protozoan parasite Trypanosoma cruzi and is spread by Triatominea or Reduviidae vectors. It is endemic to Central and South America and Mexico, where an estimated 10 million people have been infected (1). Chagas disease can also be spread by blood transfusion, organ transplantation and through vertical transmission from mother to fetus. Cases of oral transmission via contaminated fruit, fruit and sugar cane juice, and water have also been described in endemic areas (2). In the acute stage of disease, approximately $5 \%$ of those infected will experience flu-like symptoms, including fatigue, loss of appetite and fever. The first characteristic sign may be a 'chagoma', an erythematous, indurated lesion that occurs at the site of entry of the parasite, which enters the bite site via the contaminated feces of the insect. Sometimes the conjunctiva is the site of entry, and the classic painless periorbital swelling known as Romana's sign may develop (3). Acute illness more commonly occurs in children and elderly individuals in endemic areas. Treatment of acute infection with nifurtimox or benznidazole can alleviate symptoms, clear the parasite and moderate the risk of future sequelae (4).

Approximately $40 \%$ of individuals who become infected remain parasitemic but asymptomatic, and $20 \%$ to $30 \%$ progress to develop chronic infection, which results when the parasite invades the smooth muscle (2). This may result in cardiomegaly with arrhythmias and cardiac failure, megacolon or megaesophagus (3). The treatment of chronic Chagas disease remains controversial but is believed to be of benefit in patients younger than 50 years of age (5). The first case of transfusion transmission of Chagas disease was described in Brazil in 1952 (6). With increasing immigration of individuals from endemic countries to North America, it is estimated that $>300,000$ individuals infected with $T$ cruzi live in the United States (US) (7).
Several blood donor seroprevalence studies conducted in the US in the early 1990s and in 1997, showed that in some areas, such as Los Angeles (California), New Mexico and Texas, $>1.4 \%$ of donors were seropositive $(8,9)$. With the US Food and Drug Administration licensure of an assay for blood donor screening, universal donor testing was implemented by most large US blood suppliers in early 2007. Many US blood suppliers have subsequently switched to a 'test every donor once' strategy. At present, >1600 donors have been confirmed positive for Chagas disease (10). In Canada, although the rates of immigration from endemic countries are less than that of the US, of the seven reported cases of transfusion-transmitted Chagas disease in North America before donor testing, two were reported in Canada in the province of Manitoba in 1989 and 2000 (11,12). A small seroprevalence study performed in asymptomatic immigrants from endemic areas in Toronto found one positive individual of 102 tested (13). In Canada, Canadian Blood Services (CBS) provides blood products to the entire country with the exception of Quebec, and collects approximately one million donations per year. CBS implemented selective Chagas disease donor testing based on risk (identified on the donor questionnaire) in 2010.

In conjunction with the selective donor testing program, CBS also set up a donor seroprevalence survey, in which a random selection of donors who expressed no risk (answered 'no' to the three risk questions on the donor questionnaire) for Chagas disease, lived mainly in urban areas and areas where Chagas disease had been previously identified in donors in the past were tested. To achieve significance with a $95 \% \mathrm{CI}$, assuming no positives were found, it was calculated that 60,000 donors would need to be tested. Subsequently, this number was increased to approximately 100,000 to be tested by study completion, which

${ }^{1}$ Medical, Scientific and Research Affairs, Canadian Blood Services, Toronto, Ontario; ${ }^{2}$ National Reference Centre for Parasitology, McGill

University, Montreal, Quebec; ${ }^{3}$ Winnipeg Regional Health Authority Travel and Tropical Medicine Services, Winnipeg, Manitoba

Correspondence: Dr Margaret Fearon, Medical, Scientific and Research Affairs, Canadian Blood Services, 67 College Street, Toronto, Ontario

M5W 2M1. Telephone 416-313-4598, fax 416-974-9757, e-mail margaret.fearon@blood.ca 
represents $10 \%$ of the donor population. At present, $>27,000$ 'at risk' donors have been tested with 14 cases of confirmed Chagas disease being identified and $>74,000$ 'no risk' donors have been tested in the study with one donor being identified with confirmed Chagas disease, who is described in the present report.

\section{CASE PRESENTATION}

In January 2011, a blood donor involved in the seroprevalence study tested repeat reactive in the Abbott PRISM Chagas assay for Chagas antibody (Abbott Laboratories, Germany). A specimen was sent to the National Reference Centre for Parasitology at McGill University in Montreal, Quebec, for confirmatory testing. This testing included additional inhouse ELISA testing, immunoblot and polymerase chain reaction (PCR). In addition, the specimen was sent to the Blood Systems Laboratories (Scottsdale, Arizona, USA) for testing using the Ortho Trypanosoma cruzi ELISA test (Ortho Clinical Diagnostics, USA) and to Quest Diagnostics (Virginia, USA) for the radioimmunoprecipitation assay, which is routinely used for screening and confirmatory testing by US blood operators. The results of these tests are shown in Table 1.

With confirmation of the presence of Chagas antibody, the donor was contacted and informed of the results, and subsequently completed a detailed risk questionnaire. The results of this testing were communicated to her physician, who referred the donor to an infectious diseases specialist for further testing and follow-up. The donor questionnaire contained detailed questions regarding the risk for Chagas disease, including birth or residence in an endemic country, birth or residence of a mother or maternal grandmother in an endemic country (to identify vertical transmission risk), long-term travel in an endemic country ( $>6$ months) and history of previous blood transfusion. Extensive questioning of this donor revealed no identifiable risk factor for Chagas disease. Several days after the donor was interviewed, she informed CBS that her mother (a very astute nurse) wondered whether she may be the source of her daughter's infection because she had been transfused in Manitoba in 1978 and 1983 - the latter around the time of the donor's birth. The mother was subsequently tested for Chagas disease at the National Reference Centre for Parasitology using the inhouse ELISA, immunoblot, PCR and hemoculture. She was found to be positive for Chagas disease by ELISA and immunoblot; however, the PCR and hemoculture results were both negative. An extensive history revealed no risk factors for Chagas disease other than the blood transfusions received in 1978 and 1983. Unfortunately, because records of donors or recipients of blood transfusions from the 1970s were not retained by the Canadian Red Cross or the hospital or clinic where the transfusion was performed, donors and recipients of co-components could not be traced. For the transfusions in 1983, three of four donors were located and were found to be negative for $T$ cruzi antibody. Incidentally, the donor's sibling, who was born before the transfusions, tested negative for Chagas disease. The donor's son was also screened for Chagas disease and also tested negative.

The donor and her mother were referred to a regional, specialty tropical medicine clinic where they were evaluated for signs and symptoms of chronic Chagas disease. Both patients denied any history or symptoms of intestinal obstruction or constipation. The donor reported a long history of gastroesophageal reflux, which was controlled with a proton pump inhibitor. Neither patient reported symptoms of heart failure or arrhythmia, including peripheral or pulmonary edema, palpitations, syncope or chest pain. Physical examinations and routine biochemistry, hematology, and renal and hepatic function tests were normal. Investigations for infection with $T$ cruzi were described above. Both patients underwent electrocardiography, echocardiography and 24 h Holter monitoring that revealed no cardiac or conductive abnormalities. Examination of barium swallows revealed normal esophageal function. It was recommended that the donor undergo treatment to reduce the risk of progression to cardiac disease. The donor's mother was not offered treatment due to her age.
TABLE 1

\section{Confirmatory test results on study blood donor from the National Reference Centre for Parasitology (Montreal, Quebec), Blood Systems Laboratories ${ }^{\dagger}$ and Quest Diagnostics ${ }^{\ddagger}$}

\begin{tabular}{ll}
\hline Test & Result \\
\hline ELISA (inhouse, TESA antigens) & Positive \\
Immunoblot (inhouse, TESA antigens) & Positive \\
Inhouse polymerase chain reaction assay using & Negative \\
Trypanosoma cruzi primers* & \\
Ortho Trypanosoma cruzi ELISA & \\
Radioimmunoprecipitation assay &
\end{tabular}

*Trypanosoma cruzi infection of squirrel monkeys: comparison of blood smear examination, commercial ELISA and polymerase chain reaction analysis as screening tests for evaluation of monkey-related injuries (18); ${ }^{\dagger}$ Blood Systems Laboratories (Scottsdale, Arizona, USA); ${ }^{\ddagger}$ Quest Diagnostics (Virginia, USA). TESA Trypomastigote excreted/secreted antigens

The donor underwent 60 days of nifurtimox therapy $(8 \mathrm{mg} / \mathrm{kg} /$ day $)$, as recommended by the WHO. During therapy, she experienced daily nausea and vomiting and developed mild leucopenia. Her leukocyte values returned to normal after completion of treatment and the nausea also resolved.

\section{DISCUSSION}

Most North American physicians do not have experience in the management of chronic Chagas disease or the potential adverse effects of drug therapy. While all patients with acute and subacute Chagas disease should be treated, the role of treatment in chronically infected patients remains somewhat controversial. Patients with advanced age or advanced cardiac disease are unlikely to benefit from treatment $(5,14,15)$. Although most experts would agree that patients younger than 50 years of age without evidence of cardiac disease should be treated, access to the drugs required for treatment is limited, and the drugs have numerous, some being serious, potential side effects (5). In Canada, until recently, only nifurtimox was available, and only through the Health Canada Special Access Programme. Benznidazole, widely shown to be better tolerated and to have fewer side effects $(5,15)$ was out of production until early 2012. The management of Chagas disease also requires lifelong evaluation for its most common complications, which include mainly cardiac conduction anomalies, megaesophagus and megacolon. At the very least, electrocardiography should be performed yearly, regardless of the therapeutic regimen (14).

The present article describes the first reported case in Canada of vertical transmission of Chagas disease acquired through blood transfusion. Cases of vertical transmission in endemic countries are estimated to occur at rates of $0.13 \%$ to $19 \%$, depending on the country $(16,17)$. In the US, based on the prevalence rates in the country of origin of the mother and a $5 \%$ risk of vertical transmission, it has been estimated that there are 166 to 638 infected newborns (18).

ACKNOWLEDGEMENTS: The authors thank the staff of Blood Systems Laboratories for providing additional testing for our Chagas positive donors. The authors thank Ms Dolly Cordi for assistance with manuscript preparation and the donor and her mother, whose generous participation was essential to the present case report.

\section{REFERENCES}

1. Chagas disease (American trypanosomiasis) fact sheet No 340, 2012. World Health Organization. <www.who.int/mediacentre/ factsheets/fs340/en> (Accessed April 13, 2012).

2. Shikanai-Yasuda MA, Carvalho NB. Oral transmission of Chagas' disease. Clin Infect Dis 2012;54:845-52. 
3. Maquire JH. Trypanosoma. In: Gorbach S, Bartlett J, Blacklow N, eds. Infectious Diseases, 2nd edn. Philadelphia: Lippincott Williams and Wilkins, 2004:2327-34.

4. Rodriques CJ, deCastro SL. A critical review of Chagas' disease chemotherapy. Mem Inst Oswaldo Cruz 2002;97:3-24.

5. Bern C, Montgomery SP, Herwaldt BL, et al. Evaluation and treatment of Chagas' disease in the United States: A systematic review. JAMA 2007;298:2171-81.

6. Wendel S, Gonzaga AL. Chagas' Disease and blood transfusion: A new world problem? Vox Sang 1993;64:1-12.

7. Bern C, Montgomery SP. An estimate of the burden of Chagas' disease in the United States. Clin Infect Dis 2009;49:e52-4.

8. Kerndt PR, Waskin HA, Kirchhoff LV, et al. Prevalence of antibody to Trypanosoma cruzi among blood donors in Los Angeles, California. Transfusion 1991;31:814-8.

9. Leiby DA, Read EJ, Lenes BA, et al. Seroepidemiology of Trypanosoma cruzi, etiologic agent of Chagas' disease in U.S. blood donors. J Infect Dis 1997;176:1047-52.

10. AABB. Chagas Biovigilance Network. <www.aabb.org/programs/ biovigilance/Pages/chagas.aspx $>$ (Accessed April 13, 2012).

11. Nickerson P, Orr P, Schroeder ML, Sekla L, Johnston JB. Transfusion-associated Trypanosoma cruzi infection in a nonendemic area. Ann Intern Med 1989;111:851-3.
12. Lane DJ, Sher G, Ward B, Ndao M, Leiby D, Hewlett B. Investigation of the second case of transfusion transmitted Chagas' disease in Canada. The 42nd Annual Meeting of the American Society of Hematology. San Francisco, December 1 to 5, 2000.

13. Steele LS, MacPherson DW, Kim J, Keystone JS, Gushulak BD. The sero-prevalence of antibodies to Trypanosoma cruzi in Latin American refugees and immigrants to Canada. J Immigr Minor Health 2007;9:43-7.

14. Bern C. Antitrypanosomal therapy for chronic Chagas' Disease. N Engl J Med 2011; 364):2527-34.

15. WHO, 1991. Control of Chagas' disease - Report of a WHO Expert Committee. World Health Organ Tech Rep Ser 811:95.

16. WHO, 2002. Control of Chagas' disease - Report of a WHO Expert Committee. World Heatlh Organ Tech Rep Ser 905:109.

17. Yadon ZE, Schmunis GA. Congenital Chagas' Disease: Estimating the potential risk in the United States. Am J Trop Med Hyg 2009;81:927-33.

18. Ndao M, Kelly N, Normandin D, et al. Trypanosoma cruzi infection of squirrel monkeys: Comparison of blood smear examination, commercial enzyme-linked immunosorbent assay, and polymerase chain reaction analysis as screening tests for evaluation of monkeyrelated injuries Comp Med 2000;50:658-65. 


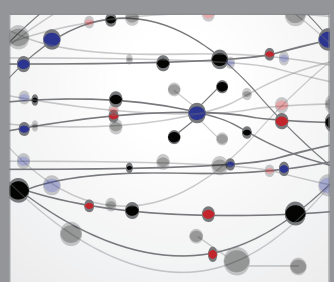

The Scientific World Journal
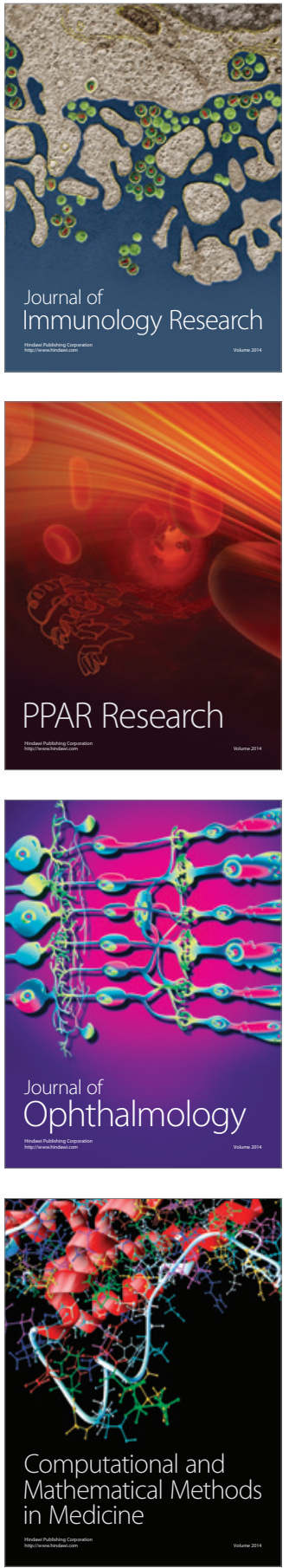

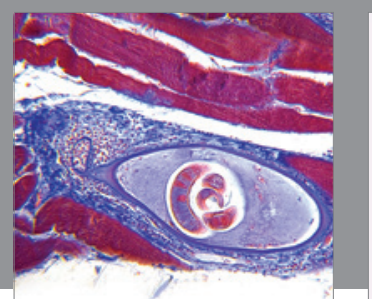

Gastroenterology Research and Practice

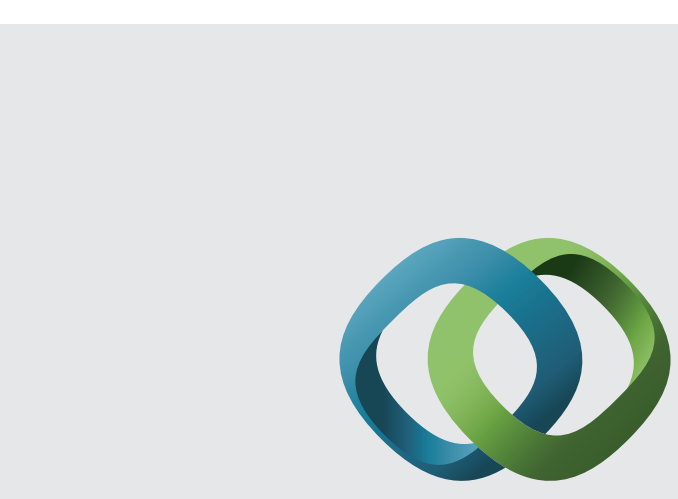

\section{Hindawi}

Submit your manuscripts at

http://www.hindawi.com
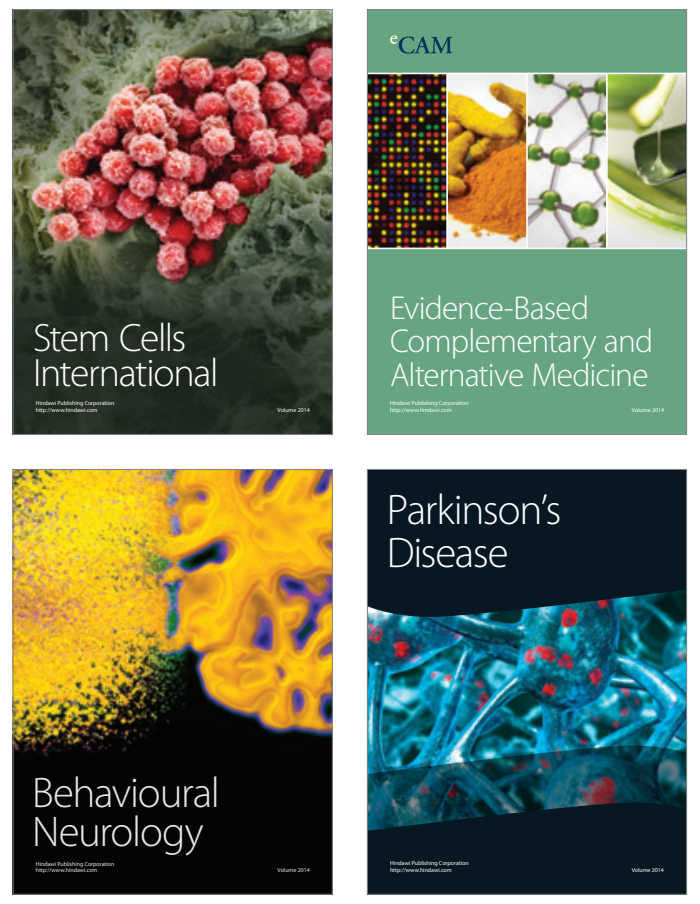
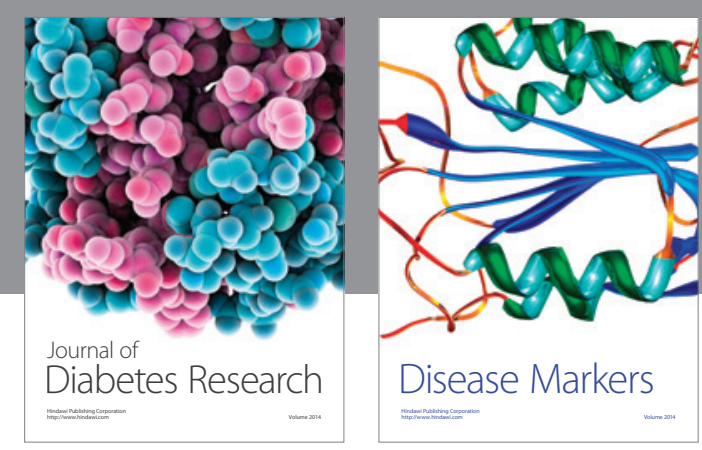

Disease Markers
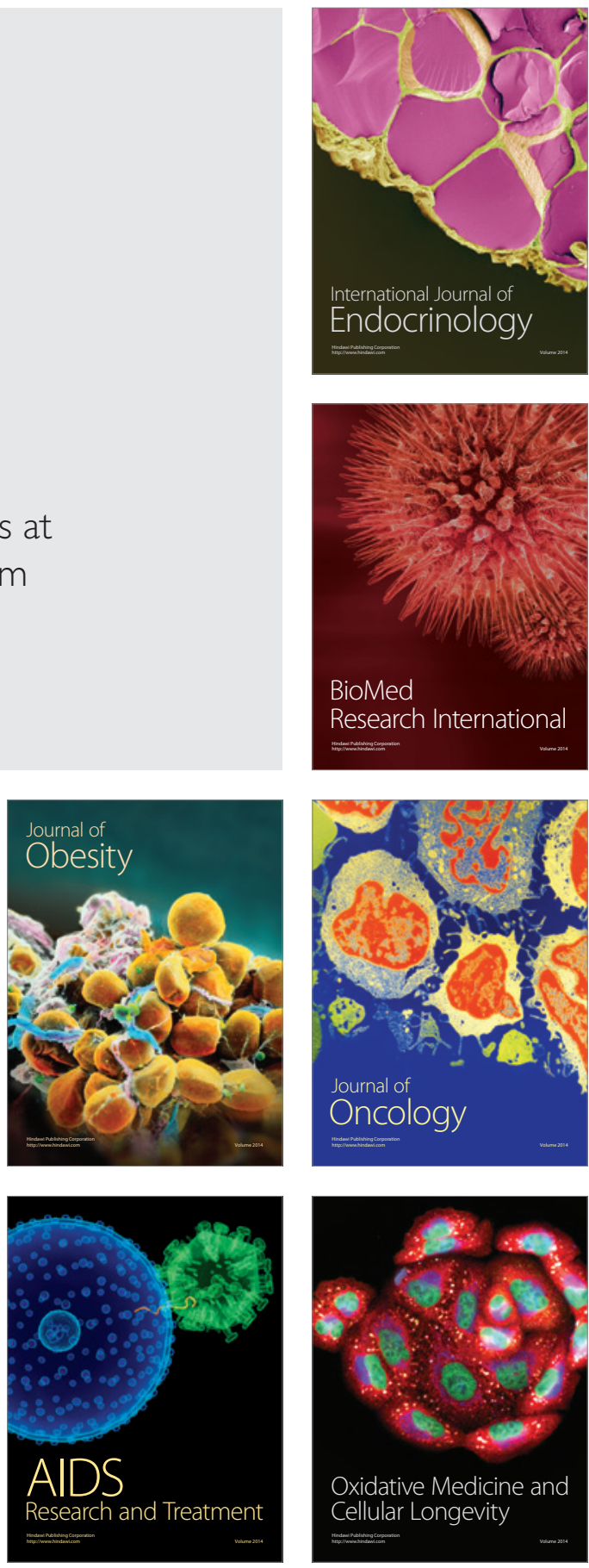